INTERDISCIPLINARIA ARCHAEOLOGICA NATURAL SCIENCES IN ARCHAEOLOGY

\title{
Analog vs. Digital Documentation - Cutting the Costs, Expanding the Possibilities. Idjoš Gradište Case Study
}

\author{
Miroslav Marića ${ }^{*}$, Jugoslav Pendićb \\ anstitute for Balkan Studies, Serbian Academy of Sciences and Arts, Knez Mihailova 35/4, Belgrade, Serbia \\ ${ }^{b}$ Biosense Institute, Zorana Đinđića 1, Novi Sad, Serbia
}

\section{A RTICLE INFO}

Article history:

Received: $1^{\text {st }}$ March 2017

Accepted: $6^{\text {th }}$ December 2017

DOI: http://dx.doi.org/ 10.24916/iansa.2017.2.2

\section{Key words:}

Neolithic

Bronze Age

Iron Age

Idjoš Gradište

image - based modelling

vector illustrations

3D models

structure from motion

\section{$A B S T R A C T$}

The article deals with the use of an integrated GIS- and image-based modelling approach to archaeological field documentation, developed for the Borderlands: ARISE project. The project, established in 2014, examines social boundaries and interactions from the early Neolithic to the Early Iron Age period in the north-east Banat region of modern Serbia. Archaeological excavations at the site of Gradište near Idjoš are at the core of the project, aimed at providing insight into the development of social identities and the manner of coexistence and interactions between different communities of various periods. Due to limited funds, the process of field documentation has been almost completely digitized, enabling fast but very precise documenting of features and finds recovered from the field: increasing the possibilities for post ex analysis, publication and presentation.

\section{Introduction}

The archaeological site of Idjoš is located $6 \mathrm{~km}$ northwest of the town of Kikinda (Figure 1), in northeast Serbia, on a slightly elevated Tisza river terrace above a confluence of two smaller streams, now culverted (Marić et al. 2016). The terrace was formed in the late Pleistocene period by the meandering of the Tisza river, which is now located about 20 kilometres to the west of the site; however, numerous traces in the landscape still show its presence barely 3 kilometres west of the site in the Pleistocene (Koprivica, Strajin 1994). It is a multi-layered site with remains of human occupation spanning from the Early Neolithic period (Starčevo/Körös culture) to the Late Neolithic period (Vinča and Tisza cultures). After a hiatus in occupation, a 250-metre diameter, sub-oval, fortified complex was constructed, belonging to the Late Bronze/Early Iron Age period (Belegiš II - Gava ceramic traditions). Sporadic Late Medieval period finds have also been occasionally recovered during surface survey prospection. The Neolithic portion of the site

*Corresponding author. E-mail: mmaric@f.bg.ac.rs was situated on the western edge of the Pleistocene terrace, above the confluence of the Grčka and Berčula streams (Figure 1, green field). This section has been called Gradište, while the Bronze Age part of the site, located immediately north-east of the Neolithic area, has been called Đurica's or the Slavic city. The Pleistocene terrace comprises mostly of river deposited sands and brown aleurite clay.

The Neolithic part of the site consists of a tell feature, roughly $60 \times 70$ metres in size, and a flat area to the north-east of it approximately $130 \times 120$ metres in size. The tell is about 2.5 meters high, surrounded by streams on three sides, and the approach to the settlement appears to have been easiest from the northeast. Immediately northeast of the Neolithic settlement, a large 250-meter diameter earthen enclosure marks the Bronze Age/Iron Age site (Figure 1). However, this settlement extends further north and northeast of the enclosure based on the preliminary results of the field and geomagnetic survey conducted in 2014 and 2015.

The first archaeological research on the site was undertaken here by Julius Nagy in 1913, but the results of these excavations were not published and the whereabouts of the finds is unknown (Girić 1957, 219). Thirty-five years 


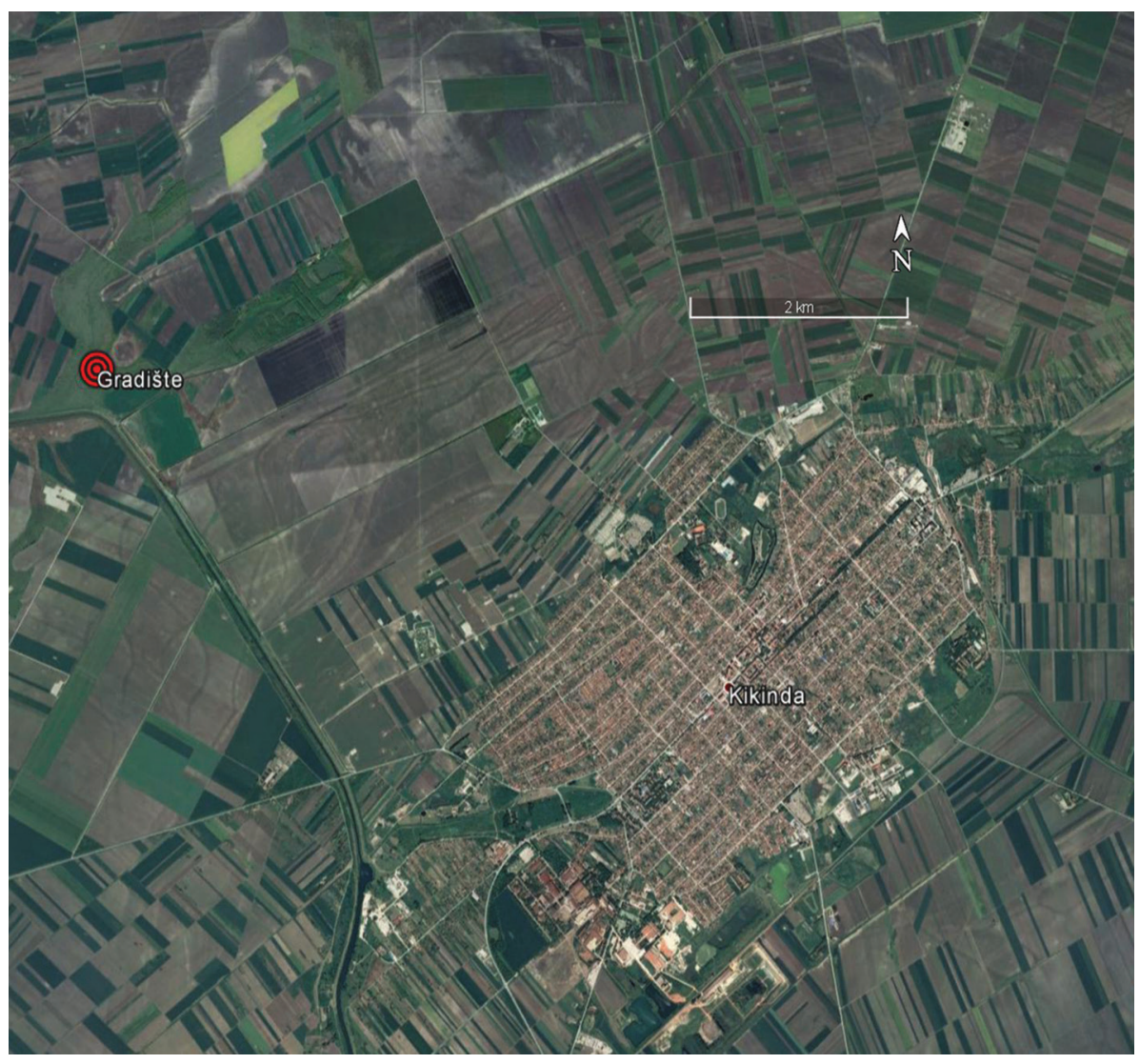

Figure 1. The location of the site of Idjoš Gradište.

later, the site was excavated by Miodrag Grbić (Grbić 1950) who, in the course of two excavation campaigns (Grbić 1951) excavated more than $300 \mathrm{~m}^{2}$ inside the circular enclosure searching for the Slavic city. In 1954, Luka Nadlački from the Kikinda Museum excavated on the tell part of the site, and discovered a wattle and daub structure in trench 3 with the remains of pottery attributed to both the Tisza and Vinča style in the same context (Girić 1957, 221-222). Almost two decades later, during 1972, a smallscale rescue archaeological excavation was undertaken at the site by the National Museum Kikinda and Provincial Institute for Protection of Cultural Monuments Petrovaradin, with 4 trenches excavated on the Neolithic settlement and others placed over a Bronze Age/Iron Age necropolis located to the southeast of the sub-oval enclosure (Medović 1984). Finally, after a four-decade long hiatus, a new research cycle was instigated in 2014, aimed at researching the Gradište site through a new, broader paradigm (The Borderlands: ARISE project, i.e. Archaeological Research of Iđoš site and its Environment). The project is envisioned as an ongoing programme to be undertaken in several stages, including evaluation of the archaeological potential of the site, targeted excavations of defined features, and broader research leading to systematic publication and public outreach. The project is focused, among other aspects, on establishing the exact character of the settlements in the distinct periods of prehistory: to better understand the site's formation and its prehistoric landscape conditions, and thus to better study and understand the life of the site and its inhabitants.

\section{Methodology}

Immediately from the beginning of the new excavations in 2014 it became clear that available funds could not facilitate having a large excavation crew with various specialists and sub-specialists waiting on standby during the excavation season. Rather, it was decided to expedite the excavation process through a simplification of excavation recording procedures. Given their cost and time-pressure, contemporary archaeological excavations require efficient and exact documentation during all fieldwork and there is thus a strong incentive for excavators to develop new techniques and methods, or refine the existing practices, for a more streamlined approach to field research. Some commercially-available software solutions, coupled with precise instrumentation used in the field, make new digital documentation techniques affordable and easily available alternatives for field research. Although digital archaeological documentation may still be regarded as a novelty, and has many potential limitations (e.g. Zubrow 2006), these obstacles are steadily disappearing with every new data acquisition technique and software package that appears on the market (e.g. Avern, Franssens 2011; Düffort et al. 2011; Motz, Carrier 2013; Smeets et al. 2013). The number of software solutions available is increasing exponentially, and it is perhaps only a matter of time before even tailor-made digital recording solutions for archaeological excavations become standard tools in the field (some solutions like ArcheoCAD, although present for a long while did not 


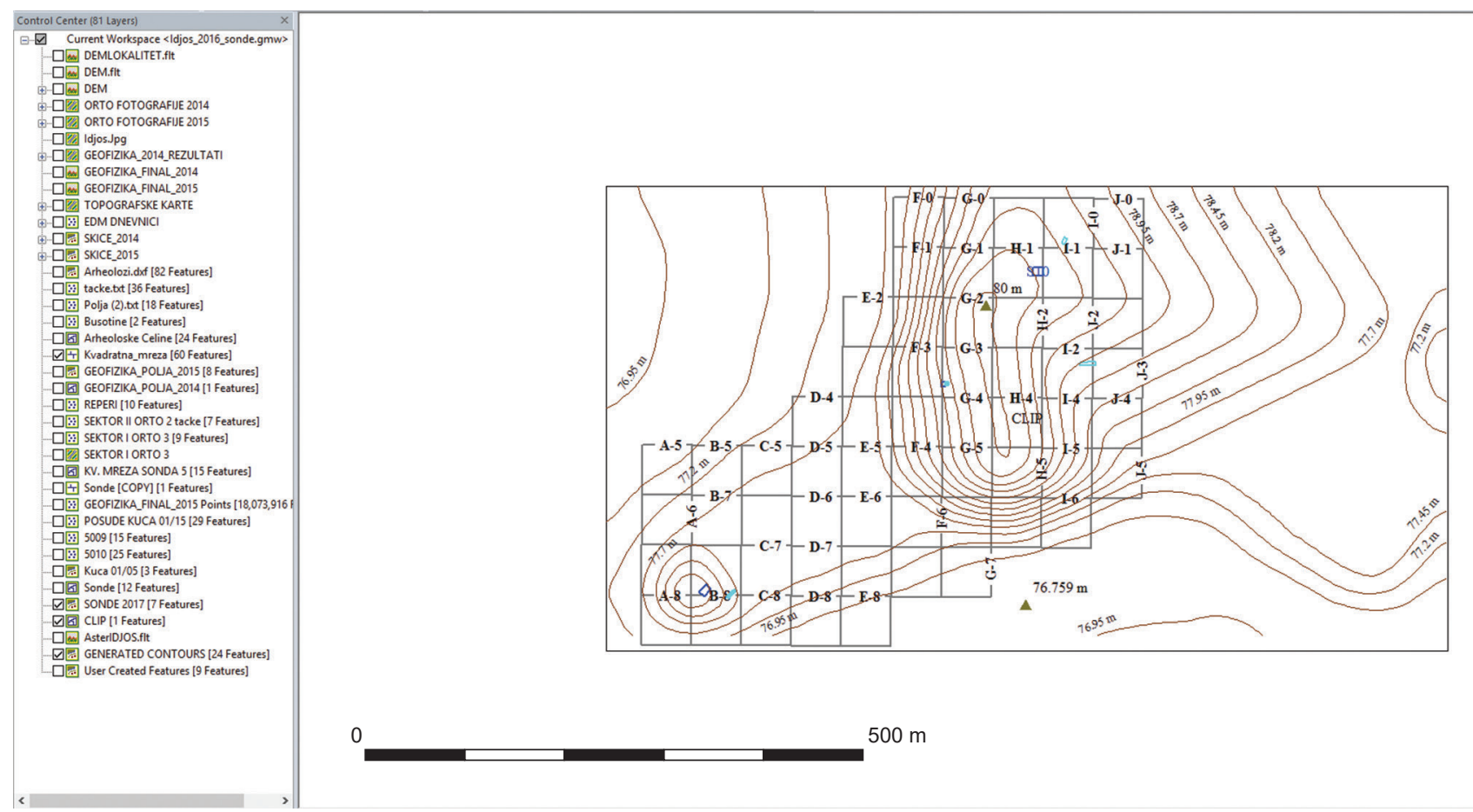

Figure 2. GIS-based documentation system used by the Borderlands: ARISE system.

become standard in digital archaeological documentation for various reasons which go beyond the scope of this paper).

In order to make the collection, storage and processing of archaeological data recorded in the field as computer and user-friendly as possible, the team opted for a commercial GIS package instead of an open source variant, but the growing number of open source solutions (products such as the long-existing Grass GIS are now being complemented by similar software like QGIS, SAGA GIS and other lessknown programs) are rapidly bringing the same level of confidence and usability to the market and could potentially lead to a complete rejection of the commercial products in the near future, due to their high cost of purchase and upgrades. Using a Harris (1989) matrix system to record the relative stratigraphy of archaeological trenches in the field, made it possible to define a series of polygons representing the outlines of features recorded while being excavated. These polygons were recorded before the excavations using a total station in the field and represent a simplified shape of the detected features. Along these geometric primitives, point data, representing individual finds, samples and other points of interest were recorded in the process, making up two of the three vector shapes any GIS software can interpret and represent. The recorded data was then organized into separate layers that could be combined to produce new, interpretative layers for spatial and statistical analysis of archaeological features (Figure 2). Each excavation season was kept separate to enable individual research per year, but features excavated over two or more seasons can also be examined jointly, either through combining data from different layers, or through the direct search capabilities of the software.
However, more complex situations in the field, that would have traditionally required an illustrator as part of the team, were treated differently. Well defined surfaces or structures were carefully excavated and cleared until a clear, in situ situation could be established. Then, instead of having a dedicated field illustrator draw a scale drawing, a process which can sometimes take several hours and completely block further excavation in the trench until finished, image-based modelling was used to create indirect documentation in the form of an orthogonal composite model. The resulting model then becomes a baseline for the creation of a drawing offsite after the excavation. Although this method is significantly faster, it is no less precise; in fact just the opposite, it is even more precise. Hand drawing is commonly based on a limited set of measurements followed by a free hand drawing of features in between the measurements by the illustrator. Some bias, or random data, is thus unavoidably input into hand drawings of even the best illustrators. Also, it is often the case that the illustrator and the excavator interpret archaeological importance differently, which can lead to some potentially-valuable information being omitted from the hand drawing (Gutehall 2016). Further, the scanning and digitization of scanned drawings can also introduce further errors or omissions into the documentation, either due to equipment or operator.

Using a 3D model as a baseline for the drawing of vector shapes is not the end product of this approach, but rather, just a step in the longer process towards obtaining a 3D surface model created through the use of specialised software such as Agisoft PhotoScan, with a relatively user-friendly interface that enables the low-cost creation of accurate 3D models from a set of digital photographs taken in a particular manner. 
In contrast to producing 2D documentation out of $3 \mathrm{D}$ content (which was in essence a standard procedure even before image-based modelling became available), an argument can be made to shift the whole process completely to 3D space. The model generated through image-based modelling is a single entity, one that is made out of particularities daub floor surface, pottery fragments, dispersed daub, postholes, daub enclosures, etc. In other words, the remains of a once functional feature; a Neolithic household in this case, are distributed as single entities that have been joined to an unclassified whole. As Wulff and Koch (2011) suggest, it is possible to use polygons (CAD utilities) collected by total station measurements, which are routinely collected during the primary documentation process, as a means to produce a classified model where each class is representing a defined feature. Additionally, using the very same polygons, one can separate the mesh into geometrically-independent units, with the special notion that should be used by a uniform projection system for data collection. However, in some countries, Serbia being one example, this kind of archaeological documentation is still not recognised by the authorities (i.e. the Ministries of Culture or other similar bodies tasked with overseeing archaeological research) as officially-required documentation, thus rendering it unusable in post excavation reporting. It is our hope that this will change in the near future.

Presently, there is a multitude of commercial and opensource software specialized for image-based surface reconstruction. Often, they can act in a complementary way alongside third-party software, to produce highly-accurate, photorealistic renderings of captured scenes. Agisoft offers arguably the most streamlined workflow, parts of which can be replaced, according to one's need, with a processing workflow coming from different software solutions, based on the user's preferences or requirements. In Idjoš, depending on the situation, Photoscan was combined with SURE (Rothermel et al. 2012), Cloud Compare (retrieved from http://www.cloudcompare.org/) and Meshlab. In the creation of the trench geometry reconstruction models, Photoscan proved more than suitable for the whole process.

\section{Results}

A burned wattle and daub structure from trench 5 , excavated in 2015, is taken as an example of this practice. The top of the burned remains was detected immediately below the modern ploughed soil layer and painstakingly cleared out until the entire boundary structure was identified (Figure 3). Upon completion, the outline of the structure was recorded using a total station to produce a polygon shape. Then, six ground control points (or GCPs; red $\times$ markers) were placed in and around the wattle and daub feature and recorded spatially with the total station, thus providing the georeferencing, measuring and scaling of the planed vector drawing, but also the base points for a 3D model. This particular number of GCPs (six) was selected based on the chosen georeferencing method, i.e. the use of trigonometric rectification.

A Nikon D3300 Digital Camera with an $18-55 \mathrm{~mm} f / 3.5$ and a $35 \mathrm{~mm} \mathrm{f} / 1.8$ Nikkor lens was used for the recording of the feature. The camera was mounted on a tripod, extended to 1.5 metres in height, which was then elevated by the camera operator to about 3 metres above the feature being recorded. A set of photographs was taken from various positions above the wattle and daub feature (Figure 4), aiming to achieve an overlapping of about $70-80 \%$ with contiguous photographs. The extent of the structure $(9 \times 6$ metres in size) was covered in total with 133 photographs, facilitating

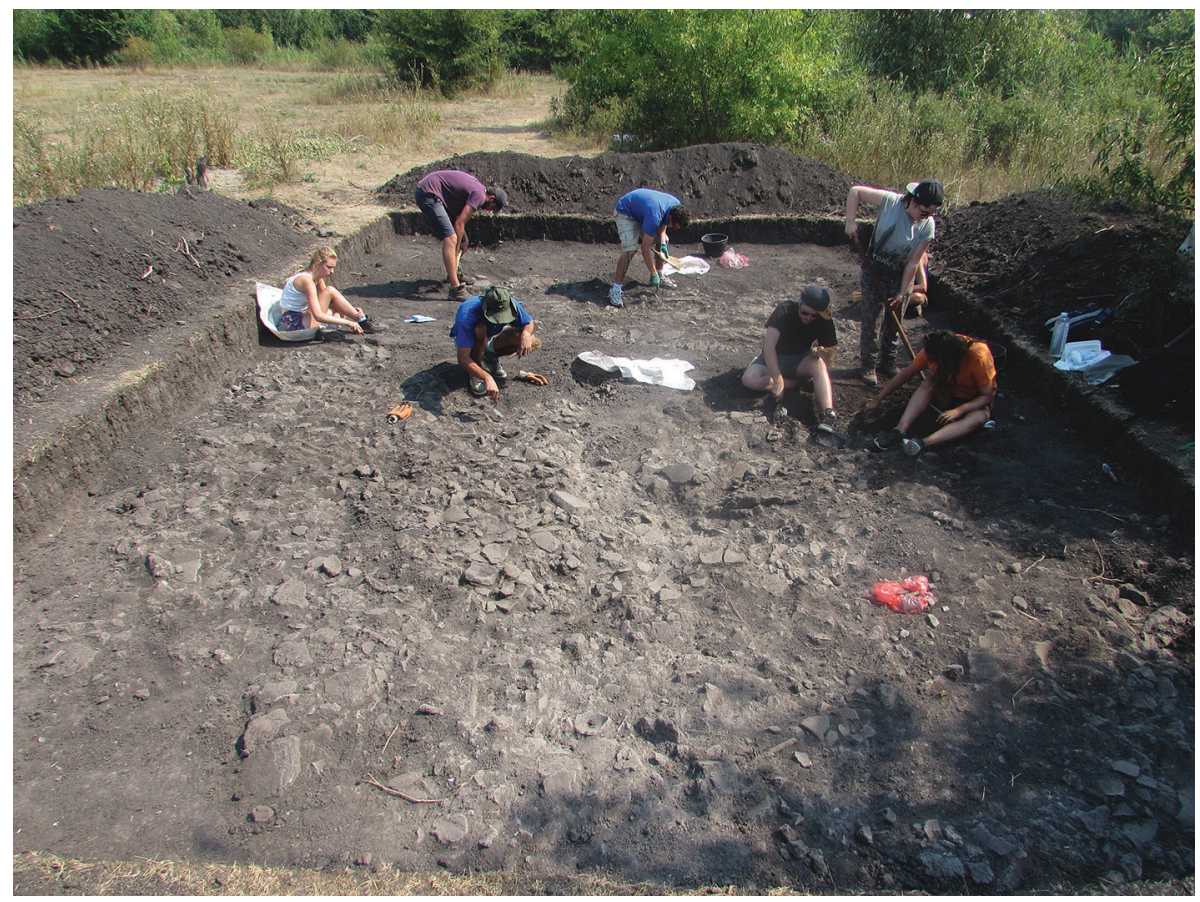

Figure 3. Excavation of the daub structure in trench 5, campaign 2015. 
Figure 4. Camera positions used to document the destruction layer of the structure in trench 5 .

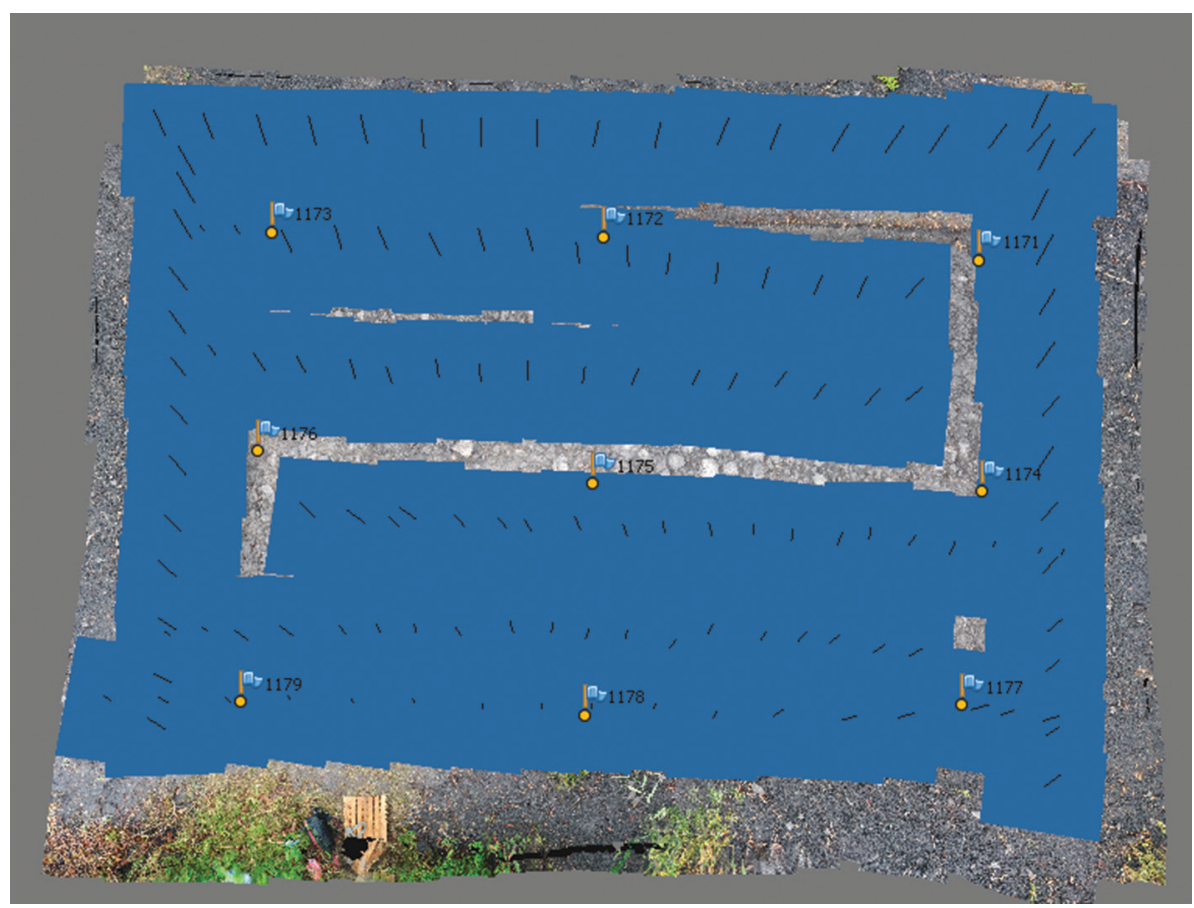

the creation of a high-precision orthogonal model. Initial processing was done on a notebook computer with Intel I7 processor, Intel HD4600 graphics adapter with $512 \mathrm{Mb}$ of VRAM and 12GB of DDR3 RAM installed. The parameters of the camera network reconstructions reported a positioning error that did not exceed 0.7 pixels of error. Network reconstruction was done with images $1 / 4$ of original size (performed automatically), and Photoscan calculated that the individual points of the trench floor surface containing the daub feature were covered with 9 or more images. The

Figure 5. Final untexturized $3 \mathrm{D}$ surface model of destruction layer in trench 5 .

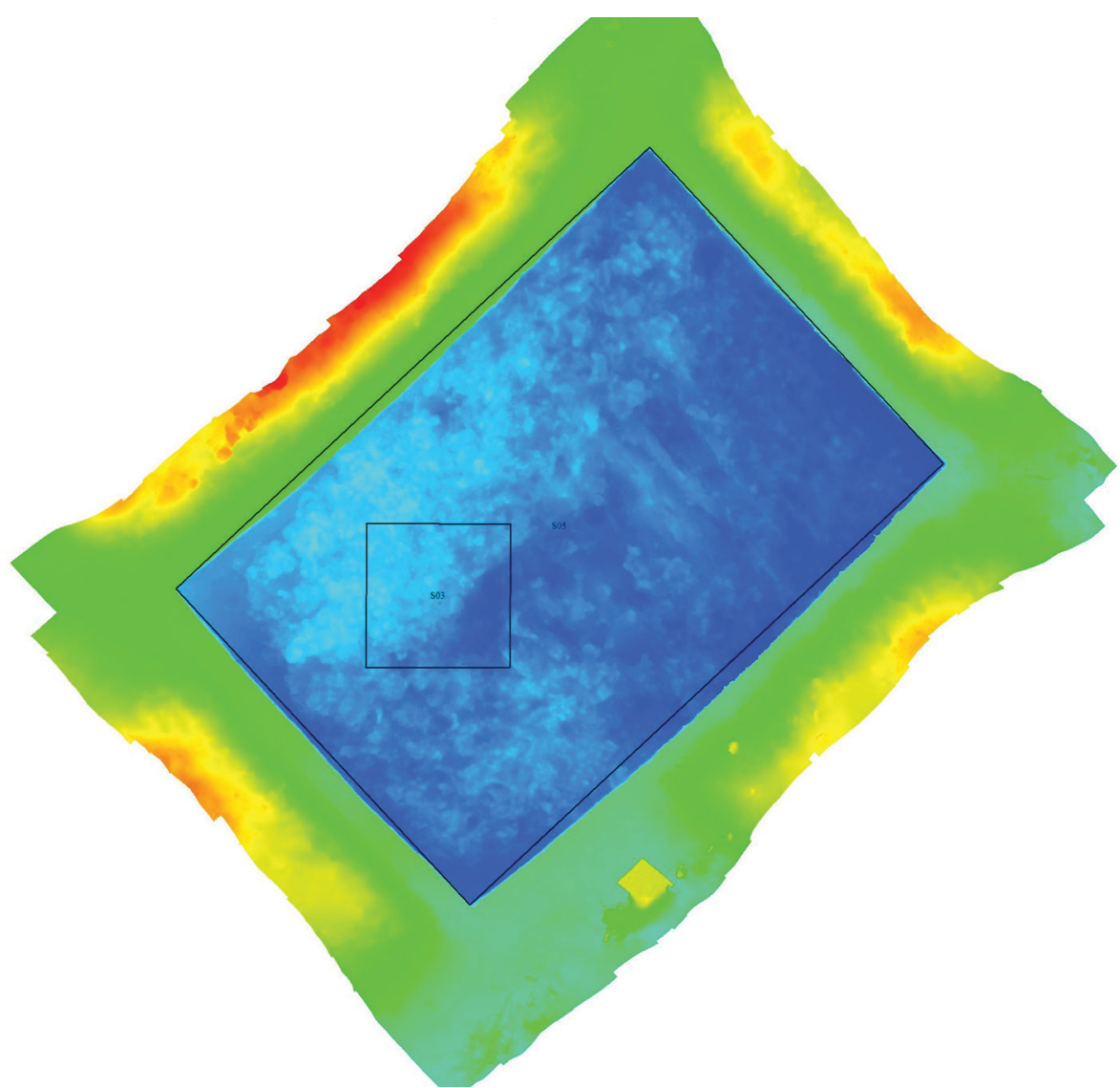


calculated error on the GCP used to reference the scene was within the 0.3 pixel boundary, with an average offset of $0.007 \mathrm{~mm}$. For reconstruction of the detailed geometry, to conserve processing time, Photoscan utilized downsized images $\left(1 / 8^{\text {th }}\right.$ of the original size $)$. This is automatically done within all commercial and non-commercial software that is on the market and is not an operation that should be performed manually by the user. Additionally, a primary documentation model, created by processing the full-resolution imagery, was created off-site. Upon completion, the model, already georeferenced by Photoscan, was exported as an orthogonal image composite, but also as a digital surface model (DSM), with pixel size $(\mathrm{m})$ of 0.0033 and a total size of $6862 \times 6704$ pixels (Figure 5). Both the orthogonal composite image and the DEM model were then loaded into a GIS program (Global Mapper) and, using the digitizer tool, a vector shape layer of the rubble layer of the wattle and daub structure was produced over the course of several days (due to the complex nature of the recorded feature it took several days to trace all the shapes). Each class of recorded material was drawn in a separate style, to easily distinguish between the different finds visible in the composite. Since the requirement for the reporting of archaeological excavations defined by the Ministry of Culture and Media of Republic of Serbia is a black and white printed drawing, the styles were adjusted to fit the requirements, using greyscale gradients for each material class. The finalised vector drawing was then exported to a PDF file and supplemented by a legend and feature information (Figure 6) to produce a standard documentation form required for reporting. Parallel to this, the excavations on the feature in the trench continued unhindered and two more orthogonal composites and DSMs were made before the feature was completely excavated.

However, the possibilities of digital archaeological documentation do not end with the production of a $2 \mathrm{D}$ scale drawing. Modern GIS software enables the overlay of two-dimensional data, such as vector shapes against a $3 \mathrm{D}$ continual surface model, leading to a new, more informative way of interpreting the archaeological data. This allows for a clearer view of the excavation results by specialists during the post-excavation or pre-publishing phases of the project. It also means that various thematic overlays can be used as additional layers of information for sharing with colleagues or the public during presentations at conferences, or over the Internet, social media and elsewhere. An example of such an overlay, illustrated in Figure 7, shows the overlay of a vector drawing over the textured DSM with particular emphasis on the pottery distribution (dark grey polygons).

The reconstruction of surfaces from imagery is based on a set of images that have been intentionally acquired for extracting precise geometry. However, in certain cases, like tourist photography (Snavely et al. 2008), archive

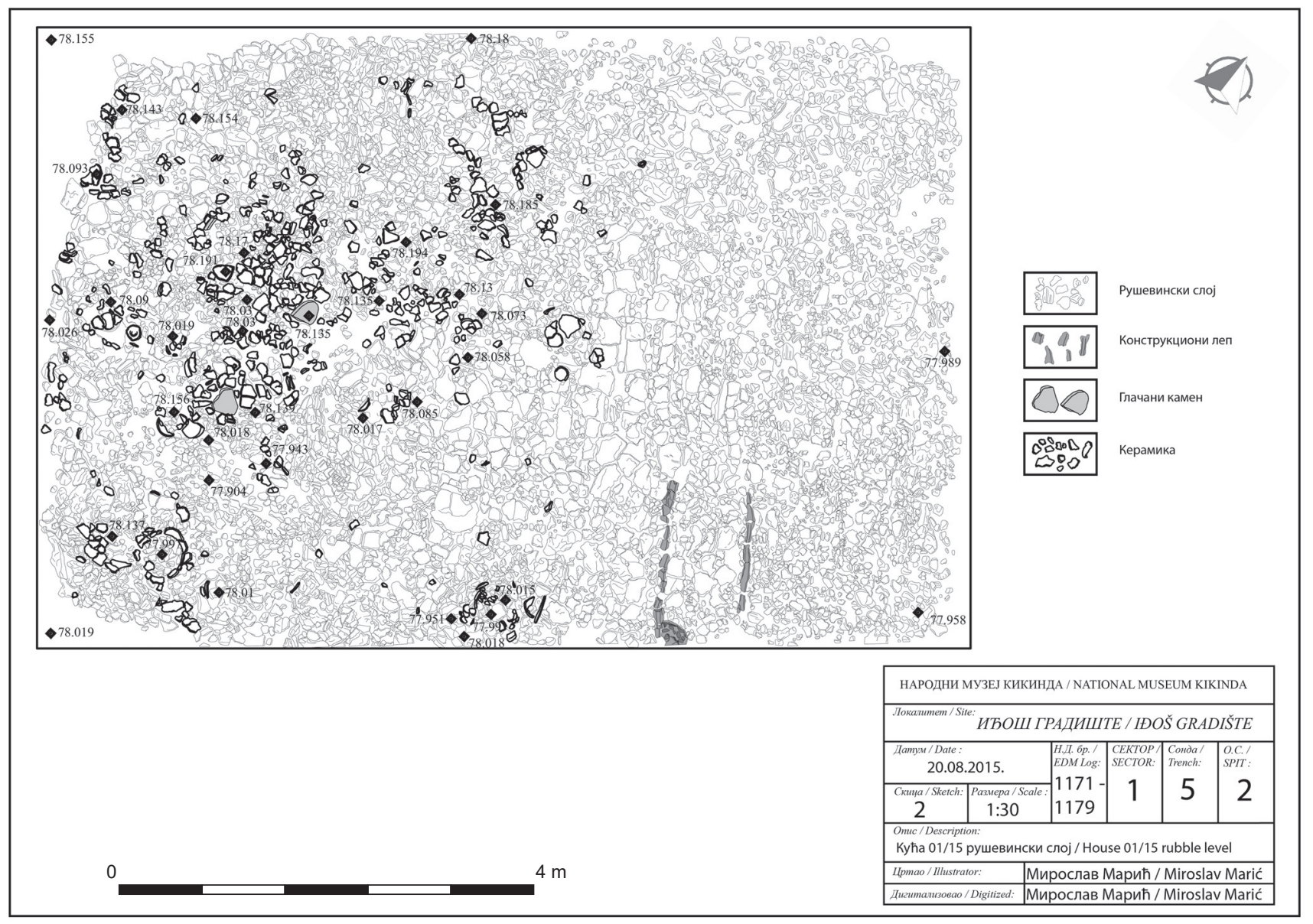

Figure 6. Final B/W scale drawing of daub structure destruction layer based on 3D texturized surface model. 


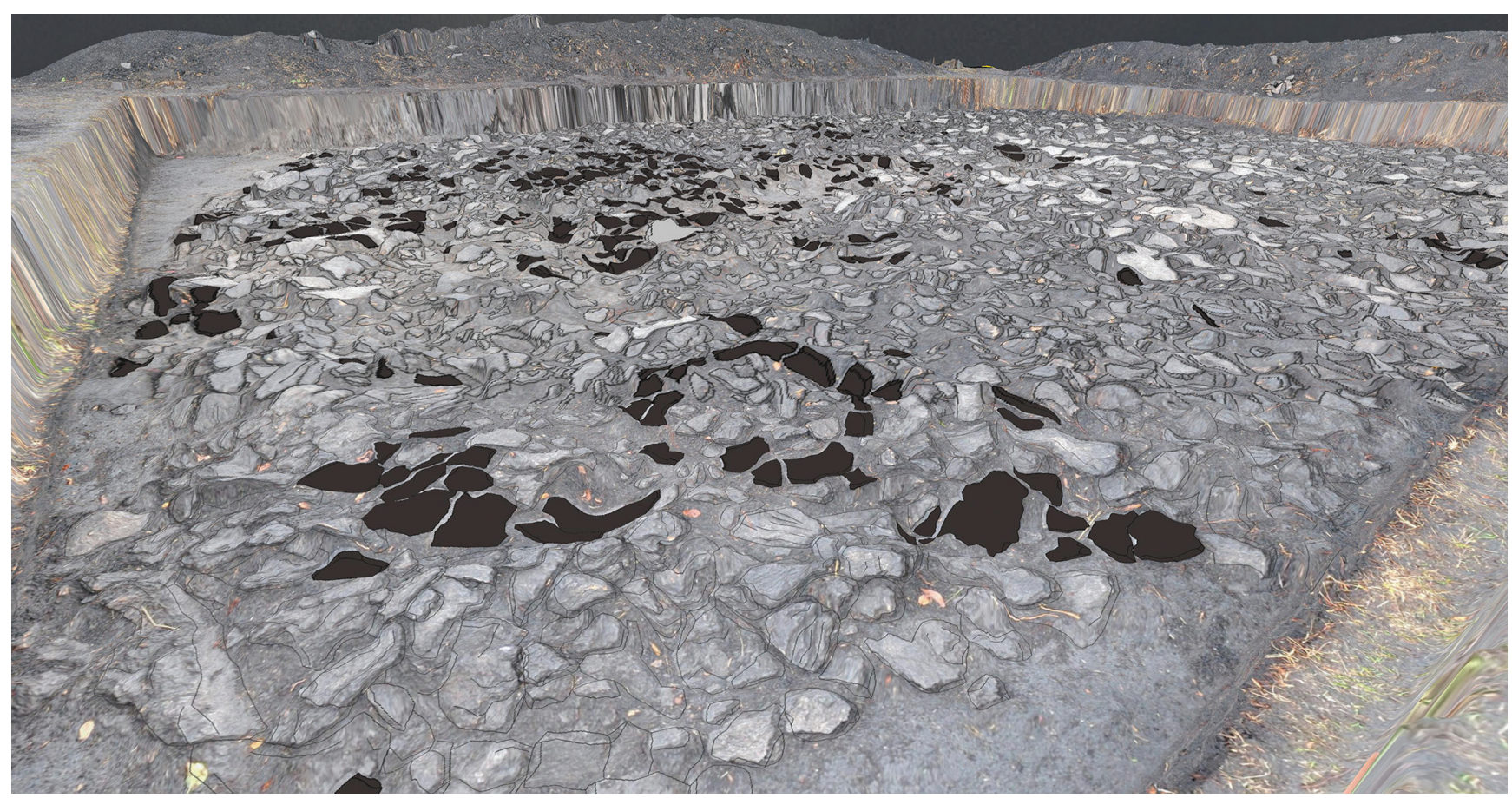

Figure 7. Detail of the overlay of vector shape layer over 3D texturized digital surface model (DSM).

photography and similar, imagery may be obtained from a haphazardly acquired set, with images covering the same object or feature by chance, rather than forethought - but this paper is not concerned with such an approach.

In Idjoš, the wattle and daub structure in trench 5 was excavated gradually, deconstructing the destruction layer one step at a time, and only after the previous step had been suitably documented with digital photos. Daub features are, as a rule, rich in prominent details, making it very easy to build up a good recognition pattern between overlapping photos. The acquisition of photographs was dependent on the sunlight conditions, the characteristics of the feature, and the time available to decrease the downtime on excavation. The structure found in trench 5, although consisting of collapsed burnt daub, was mostly planar in layout, so more often than not only orthogonal photos were required, taken

日 Orto.3.psz-Agisoft Photoscon

File Edit View Worktlow Tools Photo Help
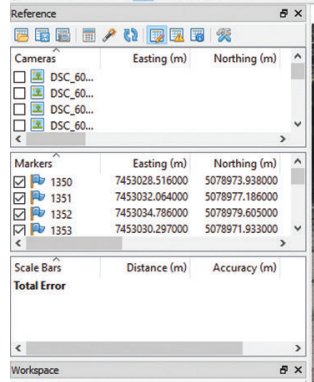

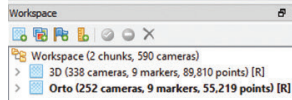

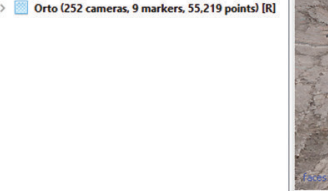

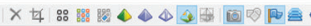

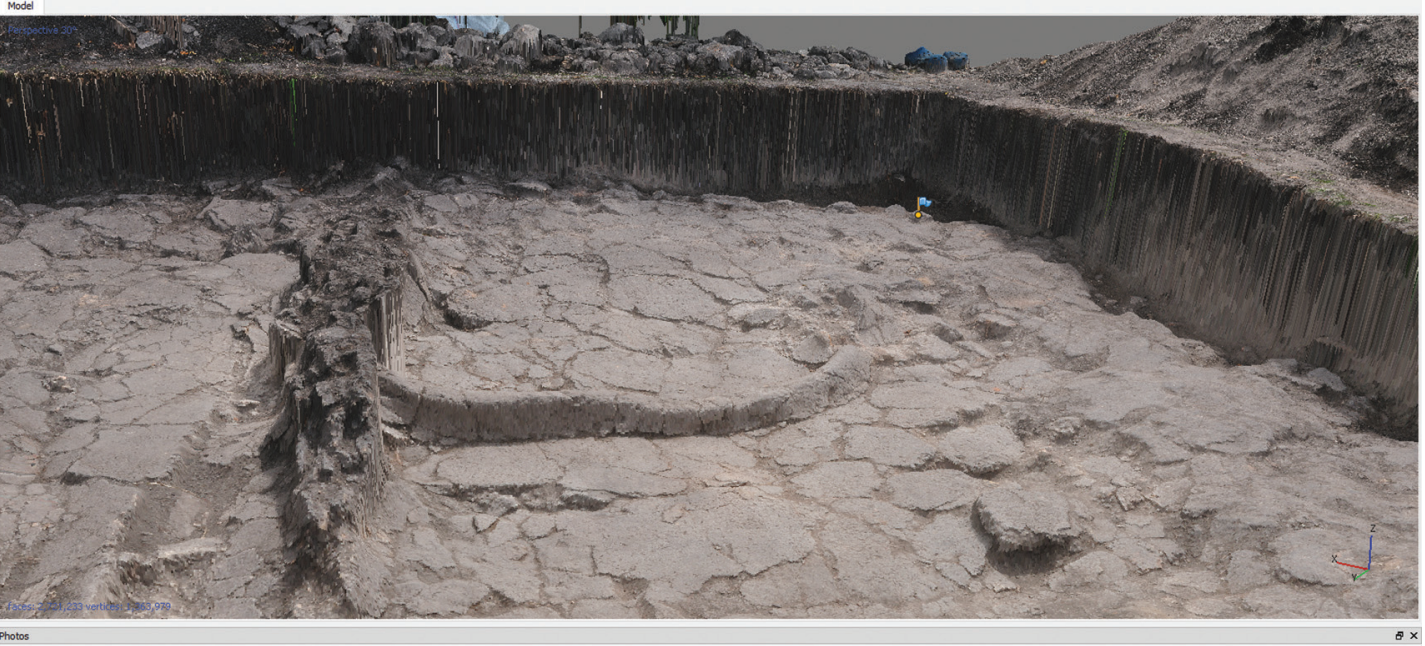

Photos

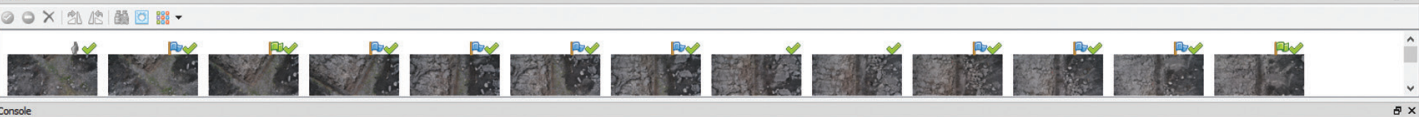

Console

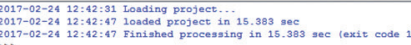

Figure 8. Vertical surfaces representation in 3D texturized DSM. 
from equal distances from a camera mounted on a hand-held tripod extended above the feature (Figure 4). However, when portions beneath the rubble layer were excavated, and the remains of a dividing wall preserved at a greater height were reached, additional sets of oblique imagery had to be taken to record the vertical surfaces not visible from orthogonal positions (Figure 8). These were recorded alongside the orthogonal during the same session, despite the angle difference between them. The combination of convergent and orthogonal imagery is important when recording complex geometry to enable adequate surface modelling: overhangs and perpendicular surfaces often require dedicated sets of photos for them to be adequately documented. In general, depending on the lens used, the image set comprised some 150 to 500 images (wide angle zoom vs prime $35 \mathrm{~mm}$ option). While a prime lens is generally better suited for documenting individual artefacts, and managing high-level precision in heritage management projects (a uniform focal length and aperture are more easily processed by imagebased modelling software because of the consistency in the photographs and lower distortion of images), no significant loss of detail or accuracy that would hamper the final model was observed during the use of either type of lens. In the case of the wattle and daub structure in trench 5 on Idjoš, the operational model of the cleared-out remains was constructed with 1,373,979 vertices, and 2,721,233 faces (Figure 9). In contrast, the primary documentation model that was constructed off-site, using full resolution imagery, contained around 298,670,503 points, that were subsampled to the number of 52,383,473 using the octree method in CloudCompare, before performing a Poisson surface reconstruction. Subsampling was done in order to avoid reconstructing models with overly densely-packed polygons that would be too complex to manipulate, with minimal improvement to the quality of reconstruction. The primary reconstructed surface model contained 26,000,000 polygons, which is far outside the limit that can be effectively operated within-a field unit. This model is not very practical for use with most everyday computer configuration, thus a simplification of the mesh was needed, which can be achieved through the process of decimation. Free open source software Meshlab (Cignoni et al. 2008) was used for decimation, geometry rebuilding and removal of erroneous polys to achieve a simpler, lighter model (Figure 10, right column). Similar to the image-based modelling software, there are various open source and commercial solutions for specific uses in the analysis of the mesh surface or editing its properties, but Meshlab provided the desired functionality for the end result needed by our project. The processed model was texturized with images that were used in its formation (Figure 10, lower right), by having texture data projected from a high-poly-textured primary model. Alternatively, it is possible to build custom UV maps to be used for texturizing - an approach that might be useful for animation projects and interactive solutions (such as VR). However, since at this stage, this was not necessary for the project, it was decided to use the simplest available solution (automatic generation of UV by using the Smart UV Project method in Blender). The final model, now simplified, can be stored in any number of formats, depending on the intended use, and can provide a basis for an animated sequence, an interactive walkthrough through the archaeological find, or even as a starting point for a virtual reconstruction of heritage for educational or promotional use at a fraction of the cost and

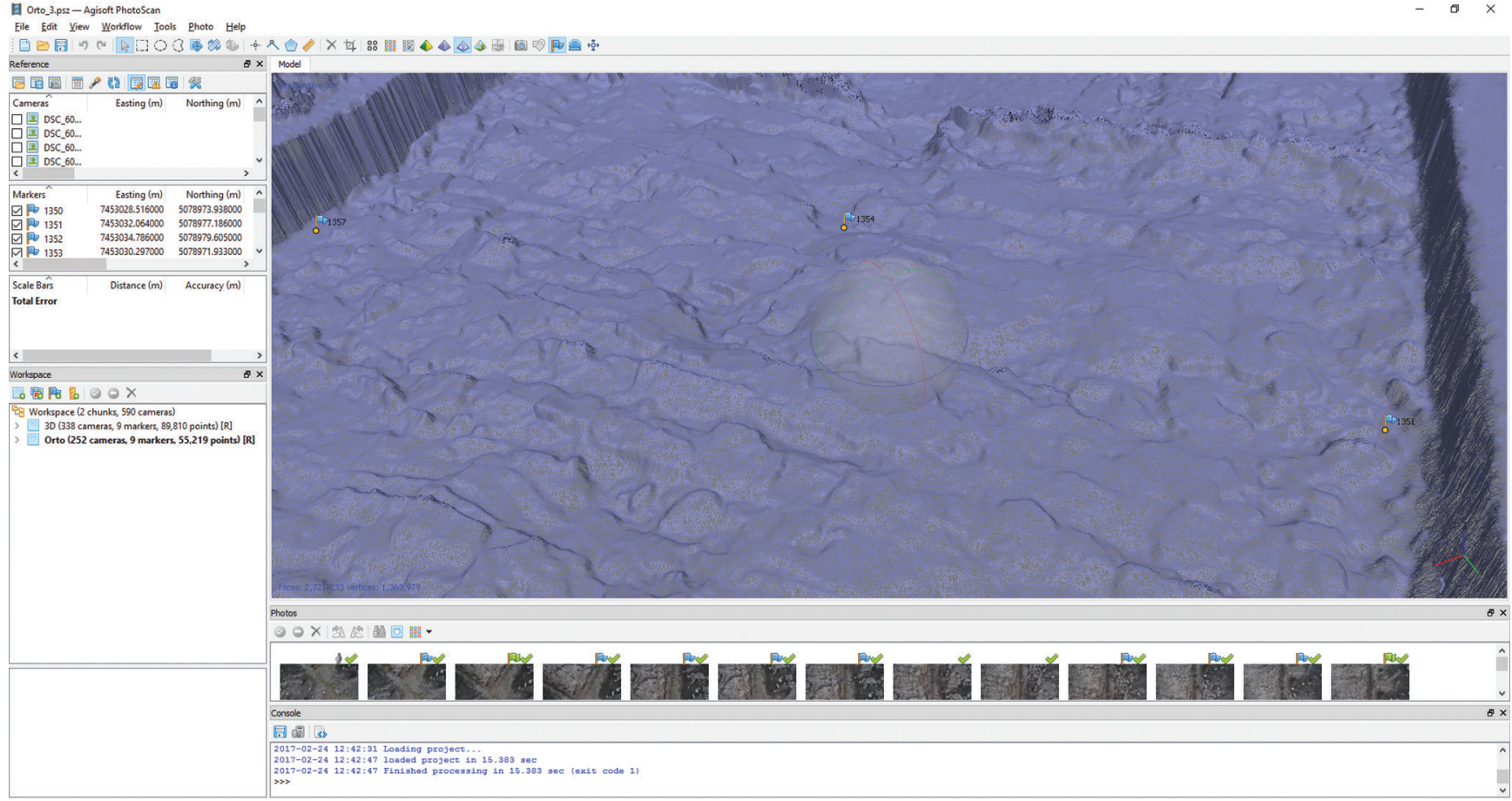

Figure 9. Untexturized mesh of daub structure in trench 5 digital surface model (DSM) created using Agisoft Photoscan. 

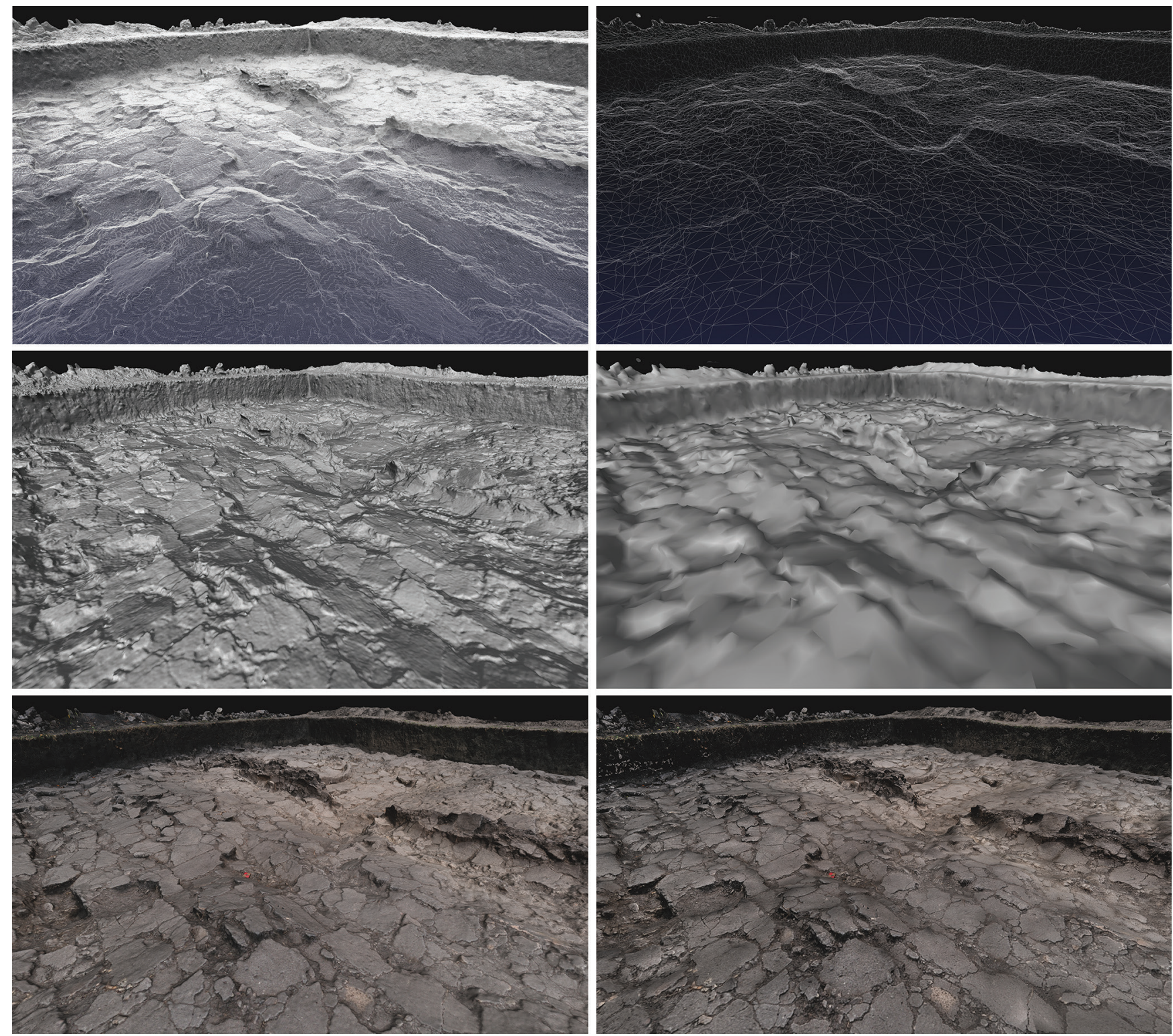

Figure 10. Undecimated and decimated models. Upper left - wireframe of primary model; upper right - wireframe of optimized model; middle left ambient occlusion shader applied to primary model; middle right - the same optimized model; lower right - texture applied to primary model; lower right - texturized optimized model (texture size 8192X8192 single untiled in both cases).

time usually needed. However, it can still be used to perform various other scientific analyses as well (e.g. Barceló 2014; Dell'Unto 2014).

The loss of detail is obvious (compare the left and right column of Figure 10), but for the purposes of visualization this is not an obstacle. Figure 11 represents various views of the excavated feature, presented using a 100,000 poly mesh that has been decimated using a Meshlab Quadric Edge Collapse Decimation algorithm. The computation of lightning conditions and a physically-realistic rendering of materials is a heavy-duty task on its own. The computational task increases with the number of polys involved, so even an operational version of the surface model ( 2 million poly) could result in a heavy toll on processing time. In this case, details from a 26 million poly surface model were projected to a 100000 poly one, to increase the speed of rendering and stability of system. The software used for visualization was Blender: it would be nearly impossible to load a primary model and effectively manipulate it in Blender workspace on a computer that was used to render the images from Figure 11 (I7, 16gb RAM, Nvidia dual GTX 980).

\section{Conclusion}

As image-based modelling is settling in to be a permanent tool in archaeological field documentation (e.g. Burke 2014; Lo Brutto, Meli 2012; De Reu et al. 2013), some basic rules are gradually being defined to deal with the proper way to document our heritage - archaeological trenches and features 


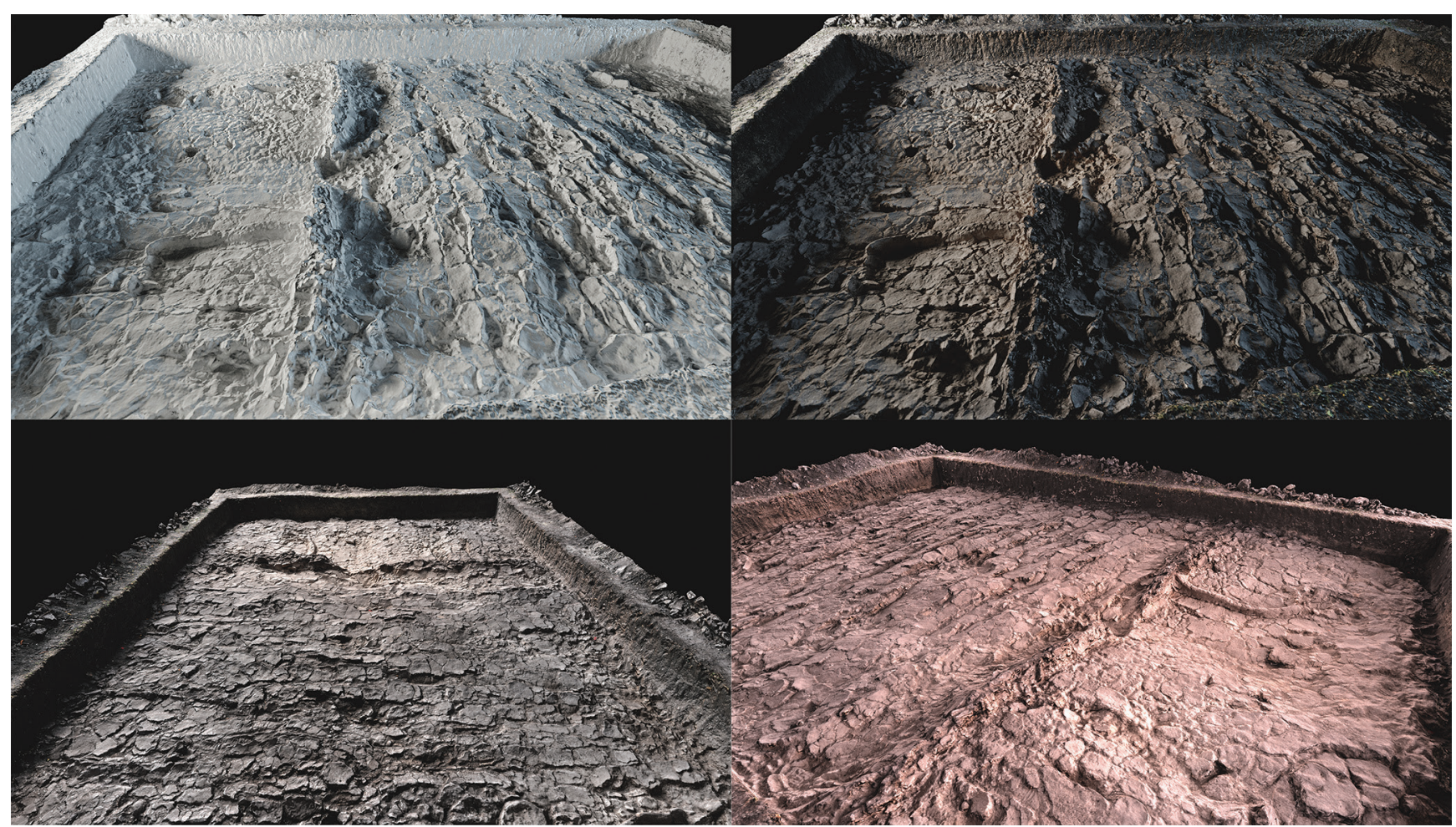

Figure 11. Decimated model, visualization. Upper left - diffuse white shader with specular map applied to surface, with details projected from primary model; upper right - the same, with texture applied to surface. Lower row: different visualizations of the optimized model.

included. While the most certain way to "get everything" is to take as many photos as one can, some pre-planning and optimization of the number of images required will reduce preparation and processing time, whilst maintaining the quality of the reconstruction just the same. Seeing that one of the benefits of the modern application of photogrammetry in archaeological documentation is to save time and funds during field excavations, transferring this step into the office, then not having control of the data load could overrule the seemingly easy solution for creating precise and cheap archaeological records.

While recording, it is important to recognize that a successful reconstruction of the camera network by the software does not necessarily mean that the final reconstruction of the surface will result in a similar success. In fact the opposite may be true; it is the quality of the individual camera positions that will be of biggest importance for a successful reconstruction: sufficient overlap, enough common features and sharp photos will be essential for the registration of photos. The weather conditions during recording are also important, as strong direct sunlight will generate deep shadows in predominantly vertical surfaces that can obliterate data and lead to a rejection of images by the program, or even modelling errors with some artefacts as descriptions of non-existing geometry occur. It should never be forgotten that dense surface reconstruction relies on the process of calculating coordinates from intersecting viewing rays, which are obtained from camera positions; or to put it another way, only points visible in at least two
2D images taken from different positions will be eligible for reconstruction - its position being at the intersection of the two viewing rays. The process is extendable to multiple images, each identified new position steadily increases the reliability of the calculation (Wenzel et al. 2012). To get a good overlap, camera stations must not be too far apart; but to get an optimal width of baseline between principal points of imagery, they must not be too close either - otherwise it is possible to get artefacts occurring within the model because of erroneously reconstructed points due to low depth precision (Wenzel et al. 2013). Certain software solutions are capable of reducing or eliminating this kind of error, by removing from the reconstruction process image pairs that are too closely positioned.

On occasion, depending on the scene being captured, raw format imagery can be of use as proprietary raw format storage: with minimum loss of information the least processed data has a wider dynamic range in the frame in comparison to the converted and processed images (e.g. jpeg). Put differently, the colour and the light intensity information are preserved in raw format images as closely as possible to the actual conditions of the actual scene. This can be used to advantage when extracting key points from darkened or shady parts of a photo. While it is desirable to have overcast conditions for good photography, this may not always be possible in the field and sometimes even with perfect conditions it is not possible to do a whole shoot in a single pass due to other reasons. Intense sunlight sometimes creates only minute obstructions in the trench that can, in most cases, be ignored; however, if the weather conditions 
are fluctuating continuously during the recording, it may be desirable to repeat the photographing process several times, and later during the modelling process eliminate potential problematic images.

Data produced from image-based modelling in Photoscan are originally in the form of a dense-point cloud format. Various programs will generate or offer an option to generate outputs that are of a specific format - for a specific application down the line. In the case of Idjoš, only a Stanford Triangle Format (.ply) with calculated normals, ready for surface building, was needed. Alternatively, depending on a project's requirements, other data formats can be of use for visualization and data control of the final product (e.g. for custom-built DEMs, DSMs or DTMs).

It is also worth noting that, unlike active methods of surface recording, image-based modelling is a passive method instead of an active light emitter as found in stationary and mobile 3D scanners, image-based reconstruction relies on the portion of light reflected in the visible (or invisible) spectrum being collected by the camera sensor, or better said, multiple camera sensor positions. In the final step of processing, multiple calculated-distance solutions are fused into one model, thus evening out the reconstructed surface and removing noise, which affects the accuracy in comparison to the real feature. This is often described as photogrammetry models having a lower conformance to the actual model, especially at the edges. The resulting point cloud is the software's very best guess of the actual geometry, and it often tends to be dubious when faced with sharp edges. This is the reason why, when comparing between identical surfaces generated with active scanning and image-based modelling, the latter will tend to leave the impression of a more smoothed product (see comparison of the LiDAR and image-based modelling 3D-model acquired of Hill of Tara in Corns and Shaw, 2013). This of course significantly depends on the equipment used in the process and the chosen recording parameters. For a simple onecamera-on-a-tripod setup, the accuracy obtained is sufficient for excavation documentation, especially when using fullresolution images. Most of the software solutions will offer an option to use downsized data for the processing stage, to speed up the workflow and reduce system-resource use. These options should be utilized with care, since too low a resolution will generate an inaccurate reconstruction, with many a fine detail lost in the modelling.

In the final stage, once a point-set mesh surface comprising of triangular polygons is built, its size depends on the density of points and the mesh level-of-detail settings. In most cases, the mesh will require optimization procedures implemented before being ready for any visual inspection. It can happen that even non-complex surfaces without geometric detail will be represented with the same numbers of polys as surfaces with more complex geometric forms. Also, the overall detail level might leave the same impression on the naked eye with 10 times less geometry density than originally envisioned. Specific to each project, such decisions on optimization must be set by consensus on the intended use of the model - for example, programs able to provide an enhanced visualization and manipulation option, such as Blender, will require the model to be below a certain threshold of complexity, in order to not consume all the operating memory in the process. The question of where does the decimation/optimisation/ simplification process exceed the need for precision in archaeological documentation is still an open issue, and no definite instructions exist to our knowledge. But oversimplification should be avoided, even at the expense of difficult data management and the slight possibility of a presentation being made without expensive specialised computer equipment. It is our core belief that at every step of the digital documentation, the initial consistency of data must be maintained to the highest degree possible; this might include the preservation of all the stages of raw to processed product made during the exercise.

\section{Acknowledgements}

The article stems from the CONPRA (Contributing the Preventive Archaeology: Innovativeness, Development and Presentation) project, supported by the Research Executive Agency within $7^{\text {th }}$ Framework Programme of the EU, the programme Support for the training and career development of researchers (Marie Curie), and the Industry Academia Partnership and Pathways (IAPP). Archaeological excavations in Idjoš Gradište were funded by the Ministry of Culture and Media of the Republic of Serbia as part of the Borderlands: ARISE (Archaeological Research of Idjoš and Surrounding Environment) project.

\section{References}

AVERN, G., FRANSSENS, W. 2011: A Digital Drawing Tool for Recording Excavations: the Nikon iSpace System. In: Verhagen, P., Mingquan Z., Romanowska, I., Zhongke, W. and Pengfei X. (Eds.): Revive the Past. Proceedings of the $39^{\text {th }}$ Annual Conference of Computer Applications and Quantitative Methods in Archaeology (CAA), Beijing, China, 12-16 April 2011. Amsterdam University Press, Amsterdam, 21-29.

BARCELÓ, J.A. 2014. 3D Modelling and Shape Analysis in Archaeology. In: Remondino, F., Campana, S. (Eds.): $3 D$ Recording and Modelling in Archaeology and Cultural Heritage. Theory and best practices. BAR International Series 2598. Archaeopress, Oxford, 15-26.

BURKE, P. 2014: Novel imaging of heritage object and sites. Proceedings of VSMM 2014 International Conference. IEE Explore Conference Publications, 25-30.

CIGNONI, P., CALliERI, M., CORSINI, M., DELlEPIANE, M., GANOVELLI, F., RANZUGLIA, G. 2008: MeshLab: an OpenSource Mesh Processing Tool. In: Scarano, V., De Chiara, R., Erra, U. (Eds.): Proceedings of Eurographics Italian Chapter Conference, Salerno. Eurographics, Salerno, 129-136.

CORNS, A., SHAW, R. 2013: Lidar and World Heritage Sites in Ireland: Why was such a rich data source gathered, how is it being utilized, and what lessons have been learned? In: Opitz, R. S., Cowley, D. C. (Eds.): Interpreting Archaeological Topography. Oxbow books, Oxford, $146-160$

DELL'UNTO, N. 2014. The Use of 3D Models for Intra-site Investigation in Archaeology. In: Remondino, F., Campana, S. (Eds.): 3D Recording and Modelling in Archaeology and Cultural Heritage. Theory and best practices. BAR International Series 2598. Archaeopress, Oxford, 151-158. 
DÜFFORT, C., BREUCKMANN, B., KALASEK, R., QUATEMBER, U. 2011: Three-Dimensional Documentation of Hadrian's Temple in Ephesus (Turkey) Using Different Scanning Technologies and Combining these Data into a Final 3D Model. In: Verhagen, P., Mingquan Z., Romanowska, I., Zhongke, W., Pengfei, X. (Eds.): Revive the Past. Proceedings of the $39^{\text {th }}$ Annual Conference of Computer Applications and Quantitative Methods in Archaeology (CAA), Beijing, China, 12-16 April 2011. Amsterdam University Press, Amsterdam, 38-47.

GIRIĆ, M. 1950: Gradište kod Kikinde. Smarunar 1, 113-118.

GIRIĆ, M. 1951: Gradište kod Kikinde. Nastavak radova u 1948. godini. Smarunar 2, 133-138.

GIRIĆ, M. 1957: Neolitsko naselje kod Iđoša (Parcijalni izveštaj o iskopavanjima u 1954. godini). Rad vojvođanskih muzeja 6, 219-230.

GUTEHALL, A. 2016. Hand Drawing Versus Photogrammetry. A Comparative Case Study of Two Techniques for Archaeological Documentation. In: Larsen, N. G., Pilati, M. (Eds.): Proceedings from the Why3D? Seminar. Øhavsmuseet Faaborgs Forlag, Faborg, 51-62.

HARRIS, E. C. 1989: Principles of Archaeological Stratigraphy. $2^{\text {nd }}$ ed., London, New York: Academic Press.

KOPRIVICA, D., STRAJIN, V. 1994: Tumač za list Kikinda (L34-77). Osnovna geološka karta Savezne Republike Jugoslavije. Savezno ministarstvo za privredu. Geokarta, Beograd.

LO BRUTTO, M., MELI, P. 2012: Computer Vision Tools for 3D Modelling in Archaeology. International Journal of Heritage in the Digital Era 1/1, $1-6$.

MARIĆ, M., MIRKOVIĆ-MARIĆ, N., MOLLOY, B., JOVANOVIĆ, D., MILAŠINOVIĆ, L., PENDIĆ, J. 2016: New results of the archaeological excavations on the site Gradište near Idjoš: Season 2014. Glasnik Srpskog arheološkog društva 32, 125-153.

MEDOVIĆ, P. 1984: Odbrambeni sistemi u praistoriji $i$ antici na tlu Jugoslavije. Referati XII kongresa arheologa Jugoslavije (Verteidigungssysteme in der Vorgeschichte und Antike im Gebiet von Jugoslawien). Arheološko društvo Vojvodine, Savez arheoloških društava Jugoslavije, Novi Sad.

MOTZ, C. F., CARRIER, S. C. 2013: Paperless Recording at the Sangro Valley Project. In Earl, G., Sly, T., Chrysanthi, A., Murrieta-Flores, P.,
Papadopoulos, C., Romanowska, I and Whitley, D. (Eds.): Archaeology in the Digital Era. Papers from the $40^{\text {th }}$ Annual Conference of Computer Applications and Quantitative Methods in Archaeology (CAA), Southampton, 26-29 March 2012, 25-31.

De REU, J., PLETS, G., VERHOEVEN, G., De SMEDT, P., BATS, M., CHERRETTÉ B., De MAEYER, W., DECONYNCK, J., HERREMANS, D., LALOO, P., Van MEIRVENNE, M., De CLERCQ, W. 2013: Towards a three-dimensional cost-effective registration of the archaeological heritage, Journal of Archaeological Science 40, 1108-1121.

ROTHERMEL, M., WENZEL, K., FRITSCH, D., HAALA, N. 2012: SURE: Photogrammetric Surface Reconstruction from Imagery. Proceedings LC3D Workshop. Berlin, December 2012, 1-9.

SMEETS, M., YPERMAN, W., AVERN, G. 2013: In Earl, G., Sly, T., Chrysanthi, A., Murrieta-Flores, P., Papadopoulos, C., Romanowska, I., Whitley, D. (Eds.): Archaeology in the Digital Era. Papers from the $40^{\text {th }}$ Annual Conference of Computer Applications and Quantitative Methods in Archaeology (CAA), Southampton, 26-29 March 2012, 25-31.

SNAVELY, N., SEITZ, S. M., SZELISKI, R. 2008: Modelling the World from Internet Photo Collections. International Journal of Computer Vision 80/2, 189-210.

WENZEL, K., ABDEL-WAHAB, M., CEFALU, A., FRITSCH, D. 2012: High-resolution surface reconstruction from imagery for close range cultural heritage applications. International Archives of the Photogrammetry, Remote Sensing and Spatial Information Sciences, 39-B5, 133-138.

WENZEL, K., ROTHERMEL, M., FRITSCH, D., HAALA, N. 2013: Image acquisition and model selection for multi - view stereo. International Archives of the Photogrammetry, Remote Sensing and Spatial Information Sciences, 40-5/W1, 251-258.

WULFF, R., KOCH, R. 2011: Towards a System for Semantic ImageBased 3D Documentation of Archaeological Trenches. In: Verhagen, P., Mingquan Z., Romanowska, I., Zhongke, W., Pengfei X. (Eds.): Revive the Past. Proceedings of the $39^{\text {th }}$ Annual Conference of Computer Applications and Quantitative Methods in Archaeology (CAA), Beijing, China, 12-16 April 2011. Amsterdam University Press, Amsterdam. 